EPJ Web of Conferences 92,02112 (2015)

DOI: $10.1051 /$ epjconf/ 20159202112

(C) Owned by the authors, published by EDP Sciences, 2015

\title{
Assessment of condensation of water vapor in the mixing chamber by CFD method
}

\author{
Petra Vojkůvková,a , Ondřej Šikula, Jan Weyr \\ Brno University of Technology, Faculty of Civil Engineering, Veveři 95, 60200 Brno, Czech Republic
}

\begin{abstract}
The analyzed topic belongs to the field of design and operation of HVAC systems, focusing mainly on mixing chambers. The paper deals with problems of condensation and freezing of water vapour on walls of mixing chambers in a special case, when the partial pressure of the final resulting state of the mixture of warm moist air and colder air is located above the saturation limit. Experimental in situ methods and computer computational fluid dynamics (CFD) modelling method were used for processing. The main contribution of this work is the finding that partial condensation and freezing of water vapour may occur in local parts of the mixing chamber. It causes problems in terms of hygienic safety and service life of these devices. In particular it has been found that condensation and freezing of water vapour may occur even if relative humidity of the resulting mixture is about $70 \%$.
\end{abstract}

\section{Introduction}

Air handling units (AHU) contain mixing chambers, which ensure mixing air flows of different temperature. A mixing ratio of the flowing air is usually designed according to the final state of a mixture without taking into account dispersion of properties. Although it seems that the final state of air is safely above the saturation curve, in certain situations condensation or freezing of local parts may occur. These undesirable phenomena have negative impact on hygienic safety of whole AHU device [1-5] and environmental quality due to their occurrence on walls of buildings $[6,7]$.

The main objective of this article is to confirm our hypothesis about possibility that the condensation of water vapour and its freezing may occur in a mixing chamber even in the case when the mixing ratio line intersects the saturation curve or forms its tangent, but the resulting state of the mixture is located in an area of unsaturated water vapour. In order to prove the hypothesis, methods of experimental measurements and numerical modelling method were used.

\section{Mixing}

Atmospheric air is a mixture of gases whose behaviour is governed by Dalton's law of partial pressures. This mixture contains water vapour, whose maximal amount is dependent on air temperature and pressure. Characteristic value describing saturated state is relative humidity, which states ratio between actual amount of water vapour and maximal amount of water vapour during full saturation. Fully saturated air (100\% saturation) cannot absorb any other moisture, which leads to condensation of water vapour and possibly to its freezing. This situation occurs throughout the entire volume of air and so called fog is formed; or surface condensation of water vapour appears on colder surfaces. These phase changes occur at temperatures below the dew point temperature and below freezing.

A mixing chamber is a sub part of an AHU and is designed for mixing two different air streams, most often fresh external air and circulating air sucked from interior. The resulting state of air after mixing is further treated in the AHU and supplied to serviced area. Diagrams allowing graphical display of changes of states of air are used in practise to determine the final state of the mixture. The most frequently used diagram in the Czech Republic is Mollier's $h-x$ diagram [8]. The point corresponding to the state of mixture after the mixing process is located at the junction of both mixed air streams and divides it into two sections, which are inversely proportional to ratios of each individual air streams.

Simplified equation for determination of the mixture temperature $t_{s}$ is applied, where $t$ states for "temperature" $\left({ }^{\circ} \mathrm{C}\right)$ and $M$ is "mass flow" $(\mathrm{kg} / \mathrm{s})$ :

$$
t_{s}=\left(\Sigma t_{i} \cdot M_{i}\right) / \Sigma M_{i}
$$

Similar equation applies to specific humidity of the mixture $-x_{s}$, where $x$ is specific humidity $\left(\mathrm{kg} / \mathrm{kg}_{\text {dry air }}\right)$ :

$$
x_{s}=\left(\Sigma x_{i} \cdot M_{i}\right) / \Sigma M_{i}
$$

${ }^{\mathrm{a}}$ vojkuvkova.p@fce.vutbr.cz 
A solution of air treatment in the $h$ - $x$ diagram can lead to 3 different cases (see figure 1a, b, c) according to parameters of mixed air flows. 1. - The mixing ratio line is located above the saturation curve. This is the desired condition without condensation of water vapour. 2. - The mixing ratio line is tangent to the saturation curve. 3. - The mixing ratio line intersects the saturation curve, the final state after mixing is located in the area of unsaturated air - there is a risk of condensation of water vapour. 4. - The mixing ratio line intersects the saturation curve, the final state of air after mixing is located in area below the curve - there is condensation of water vapour and also formation of fog in the mixing chamber.

Conditions for condensation of water vapour in mixing chambers occur mainly in winter season, when the outside air temperature drops to low values and the cold air intake from outside is mixed with hot and very moist circulating air. In this case the mixing ratio line of mixed air flows intersects the curve at $\varphi=100 \%$ and position of the state of air after mixing depends on mass ratios of mixed air flows.
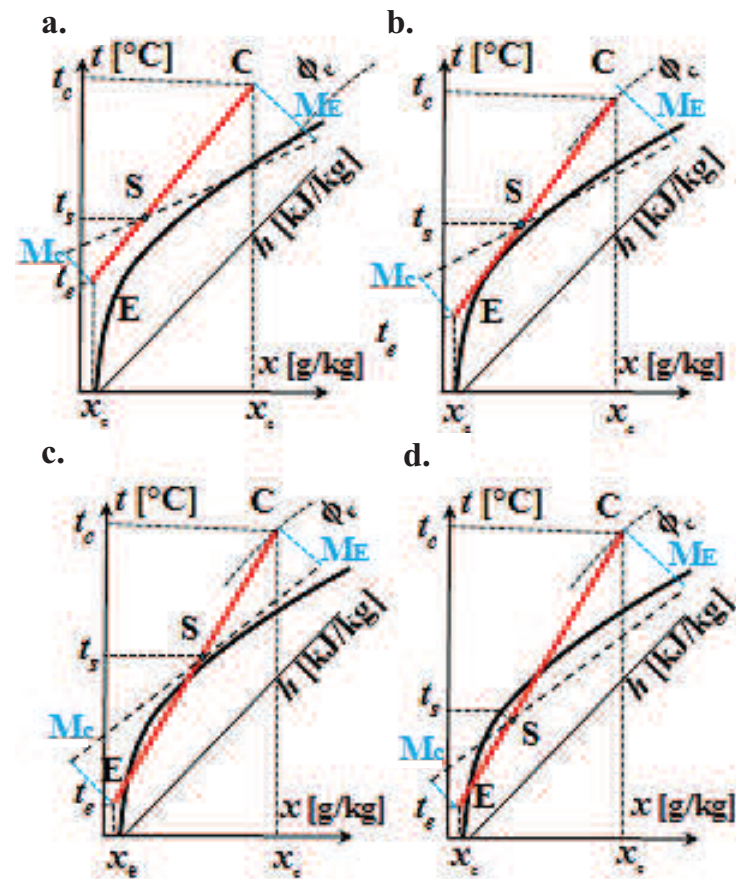

d.

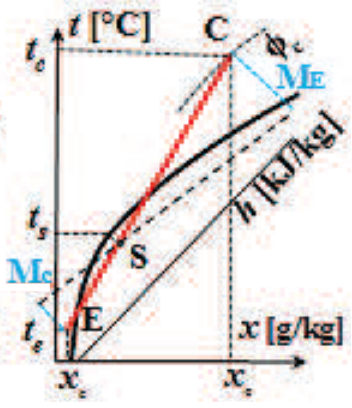

Fig. 1. a. Mixing ratio line and final state of air after mixing is located above saturation curve $b$. Mixing ratio line is tangent to saturation curve c. Mixing ratio line intersects saturation curve, final resulting state after mixing is located in area above saturation curve d. Mixing ratio line intersects saturation curve, final resulting state after mixing is located in area below saturation curve.

\section{Experimental part}

To verify the hypothesis about formation of condensation or freezing of water vapour, we sought an air handling unit working over a long period (several years) in favourable heat-humidity conditions. The selected AHU operates in climate area with outside design temperature less than $-15{ }^{\circ} \mathrm{C}$ and is designed to produce warm moist air for technological purposes of approximately constant parameters. The experimental part consists of following three parts.

In the first part we carried out a short-term measurement for one week during winter season. Values of humidity and temperature and experimentally also air flow rates were measured. The aim of this first part was to examine the distribution of temperature and humidity in the mixing chamber area and on its surfaces.

The second part consisted of evaluating data from a building management system (BMS), which records selected operating parameters in a long-term period. The aim was to verify whether risk parameters of air in terms of condensation and freezing are reached in winter period.

The third part was visual inspection of the whole AHU device and its mixing chamber, especially in order to find direct or indirect evidence of irregular distribution of temperature and humidity with respect to condensation and freezing of water vapour in air. The assessment was based on assumption that there would be certain significant change on surfaces where condensation and freezing occurred after long-term operation, such as corrosion, higher level of contamination or macroscopically visible growth of microorganisms.

\subsection{Characteristics of air handling unit}

AHU is a modular unit, which provides air conditioning for technological processes requiring yearround air humidification of supplied air to the operated space. There is a fan on its entry, which sucks $46000 \mathrm{~m}^{3} / \mathrm{h}$ of air from interior with relative humidity of $51 \%$. This air enters a mixing chamber, where it is divided in ratio $3: 7$ to waste air stream 0 and circulation air stream $\mathrm{C}$. The waste air stream is conducted through the upper part to exterior by ducts, while the circulation air is blown into a second mixing chamber, where it is mixed with fresh air from exterior (air stream E) of low temperature and low relative humidity. Further off, the mixture continues through a filter to an air washer, a heater and is supplied by a fan to the operated space through ventilation ducts (figure 2). Dimensions of the mixing chamber are presented in the figure 3 according to manufacturer's drawings. The whole air handling unit has been located in the HVAC machine room and has been operated under these conditions for approximately 20 years.

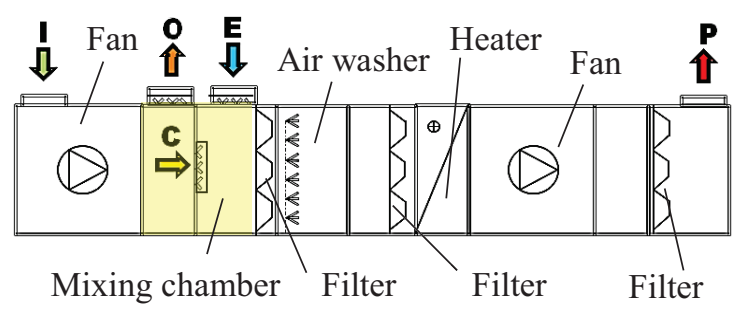

Fig. 2. Composition of examined AHU 
a.

b.

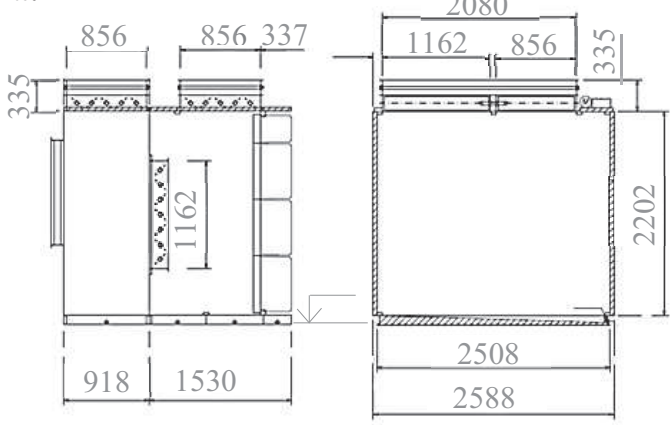

Fig. 3. a. Longitudinal section of mixing chamber, b. Cross section of mixing chamber

The experimental measurements were carried out in the mixing chamber for determination of temperature and humidity of entering air streams and surface temperature of the mixing chamber. The measurements should verify our assumption that condensation is formed on the surface walls of the mixing chamber. The actual measurement process was preceded by a visual control, which found a corrosive condition. The area most affected by corrosion was located on a flange of the flap, by which the fresh air is supplied from the outside (figure 4). The result of this process was paint-peeling and creation of typical surface brown-coloured stains. Lower damage was found on back side of the chamber; the side above the circulation flap and bottom part of the chamber showed no signs of corrosive attack. a.

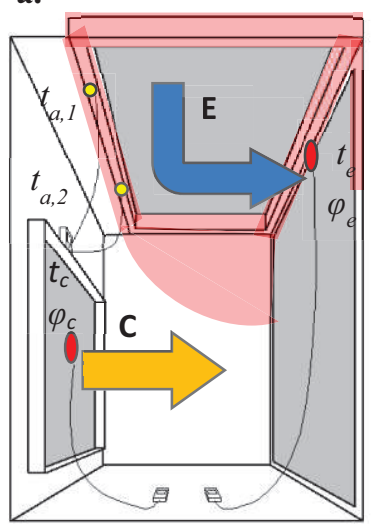

b.

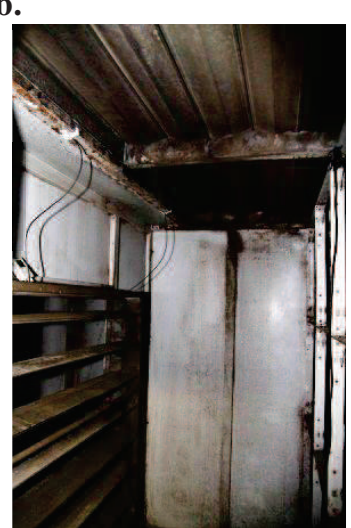

Fig. 4. Display of areas affected by corrosion and position of sensors a. Graphic illustration b. Photo of actual state

Single time point measurement values with the lowest measured external air temperature and the highest humidity of the circulating air were selected from the whole data set. Data obtained from long-term measurement (from building management system - BMS) were used for further evaluation of condensation or possible freezing, because appropriate thermal-humidity conditions (figure 5) did not occur during short-time measurement. a.

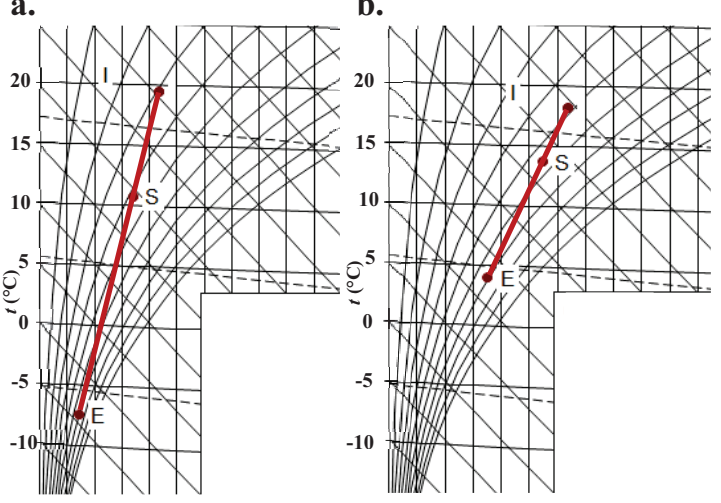

Fig. 5. Construction of mixing ratio line of obtained data: a. The lowest temperature of external air, $b$. The highest humidity of circulation air

\subsection{Assessed states of air}

The air treatment occurring in the mixing chamber was plotted into the $h-x$ diagram to determine the final state of air and position of the mixing curve to the saturation curve in the diagram. Two models differing in temperatures of the external air were created in order to compare the possibility of condensation at different temperatures. The first model operated with external air temperature $-10 \quad{ }^{\circ} \mathrm{C}$, the second one with temperature $-5{ }^{\circ} \mathrm{C}$ (winter design temperature of the climate area). For both cases the relative humidity of external air was equal to $80 \%$.

Climate data were observed during year 2012 in the given area. This observation showed that incidence of temperature below $-10^{\circ} \mathrm{C}$ is 208 hours per year and 45 hours for temperature below $-15{ }^{\circ} \mathrm{C}$. Figure 6 illustrates the lowest daily temperatures for the reference period of one year.

Parameters of exhaust air from the inside were deducted from BMS device controlling the AHU. The intake air temperature during data readout was $+5.0^{\circ} \mathrm{C}$. Due to the character of operation (high heat production) it is assumed that neither the temperature nor the humidity of exhaust air will change during outside temperatures $-10{ }^{\circ} \mathrm{C}$ and $-15{ }^{\circ} \mathrm{C}$. Structure of the $h$ - $x$ diagram is based on [8].

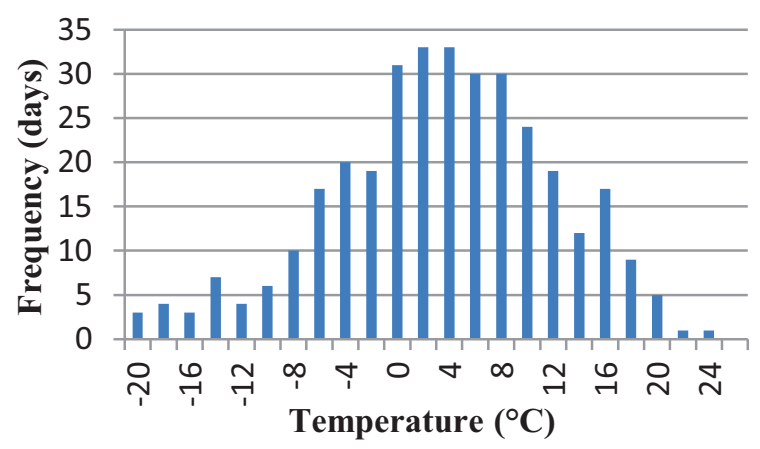

Fig. 6. The lowest daily temperature in year 2012 for given climatic region 
Figure 7 and 8 documents the course of air treatment in $h-x$ diagram and construction of the mixing ratio line with the resulting state of the air mixture. The mixing ratio of outside and circulation air flows was selected as $3: 7$ with respect to the required flow of the fresh air.

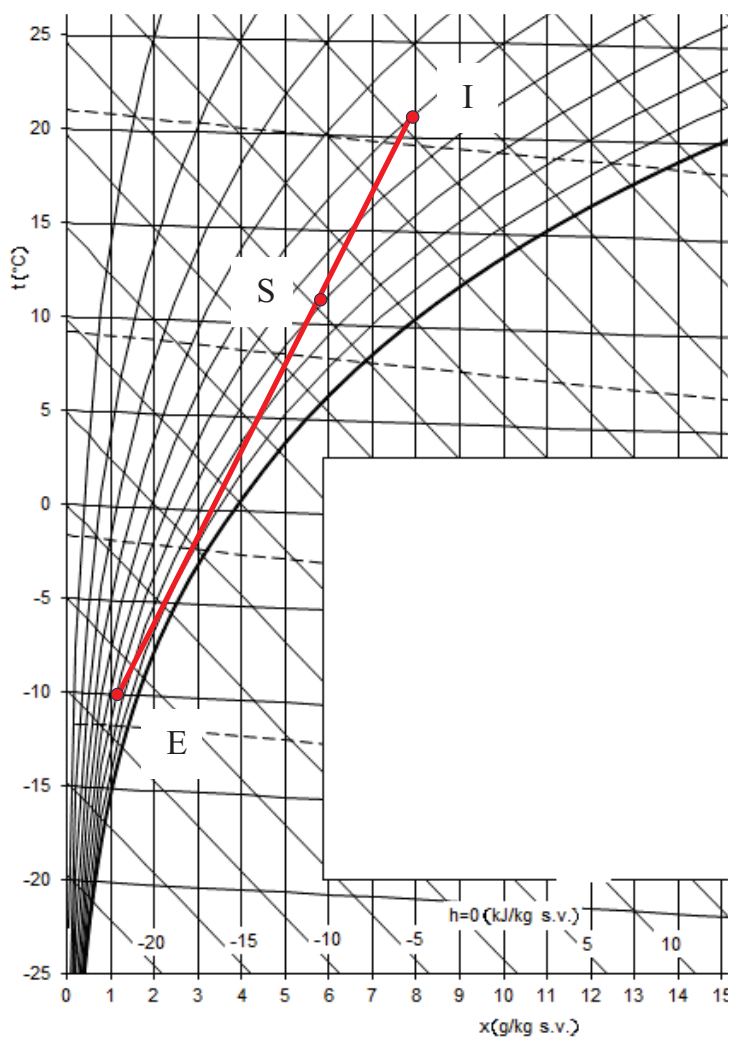

Fig. 7. Variant $1-$ temperature of external air $t_{e, 1}=-10{ }^{\circ} \mathrm{C}$

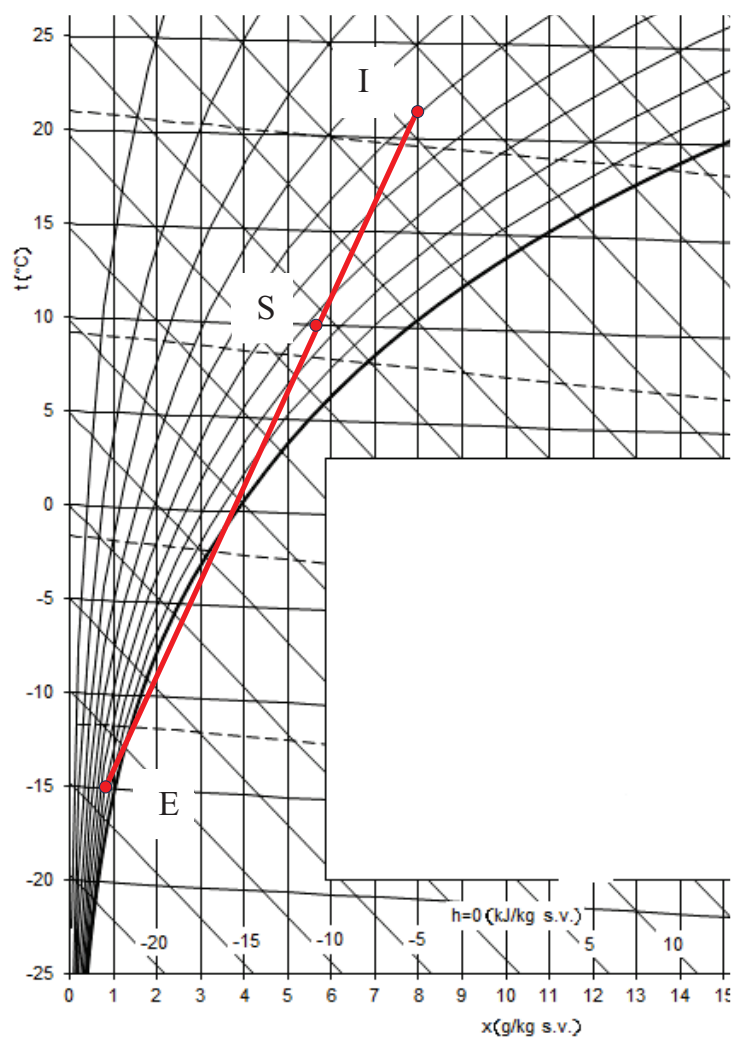

Fig. 8. Variant 2 - temperature of external air $t_{e, 1}=-15^{\circ} \mathrm{C}$
In both cases the resulting state is located above the saturation curve. This would support our hypothesis that the corrosion inside the mixing chamber may be formed as a result of condensation and freezing of water vapour on its walls. Position of the mixing ratio line to saturation curve is no longer identical. In design state 1, for the external temperature $-10{ }^{\circ} \mathrm{C}$, the mixing line segment of mixed air streams passes above the saturation curve. While in the second case, for the external temperature $-15{ }^{\circ} \mathrm{C}$, mixing line segment intersects the curve.

\section{CFD simulations}

Assessment of the possible surface condensation on walls inside the mixing chamber during these defined air parameters - which leads to corrosion - was solved by computer computational fluid dynamics method (CFD method). This method is convenient for these purposes as demonstrated in publication [9] and [10]. The calculation was made in a commercial program code of ANSYS Fluent. The aim of the CFD simulation was to set out in detail the distribution of temperature and humidity in the mixing chamber and in areas with relative humidity higher than $100 \%$.

\subsection{Geometric and boundary conditions}

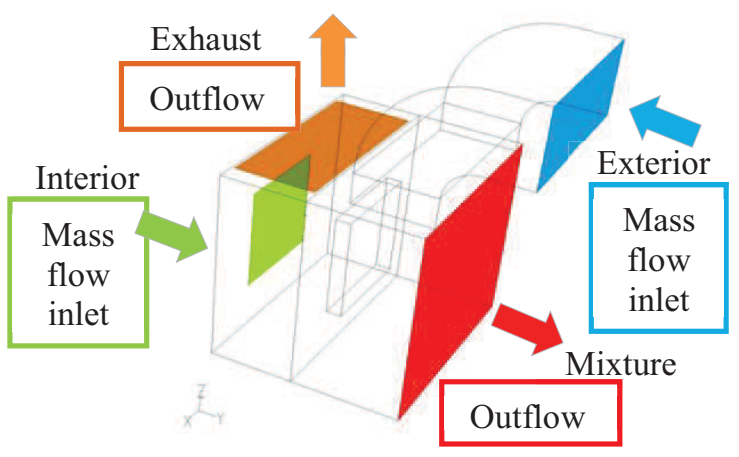

Fig. 9. Types of boundary conditions

Geometry of the chamber was entered according to project documentation of the AHU (figure 3) and topped up by part of the suction pipe. Structured network was used. Simulations were made for both design conditions of air, outdoor temperatures $-10{ }^{\circ} \mathrm{C}$ and $-15{ }^{\circ} \mathrm{C}$. In model was considered incompressible mixture of ideal gases. A stationary calculation was chosen with time-steady air flow and influence of turbulence and thermal radiation. Used model of turbulence was $\mathrm{k}-\varepsilon$ realizable. Turbulence at the entry was entered with intensity and by the characteristic dimension, which forms the short dimension of the inlet opening into the mixing chamber. In inlet was chosen boundary condition mass-flow-inlet, where specifying the mass flux permits the total pressure to vary in response to the interior solution [11]. Firstorder upwind scheme was used for numerical discretization. The other most important setting parameters are listed in table 1. Fully converged state was achieved in both cases by using iterative solver. 
Table 1. Setting parameters

\begin{tabular}{|c|c|c|c|}
\hline Solver & $\begin{array}{l}\text { Type } \\
\text { Formulation } \\
\text { Time } \\
\text { Gradient } \\
\text { option } \\
\end{array}$ & $\begin{array}{l}\text { Pressure-Based } \\
\text { Implicit } \\
\text { Steady } \\
\text { Green-Gauss node } \\
\text { based }\end{array}$ & \\
\hline $\begin{array}{c}\text { Turbulent } \\
\text { model }\end{array}$ & $\mathrm{k}-\varepsilon$ & $\begin{array}{l}\text { Realizable } \\
\text { Standard wall } \\
\text { functions }\end{array}$ & \\
\hline $\begin{array}{c}\text { Species } \\
\text { model }\end{array}$ & $\begin{array}{l}\text { Species } \\
\text { Transport }\end{array}$ & mixture-template & $\begin{array}{l}\mathrm{H}_{2} \mathrm{O} \\
\text { air }\end{array}$ \\
\hline Material & Mixture & default & \\
\hline $\begin{array}{l}\text { Operating } \\
\text { conditions }\end{array}$ & $\begin{array}{l}\text { Pressure } \\
\text { Gravity }\end{array}$ & $\begin{array}{l}101325 \mathrm{~Pa} \\
\mathrm{z}\end{array}$ & $-9,81 \mathrm{~m} / \mathrm{s}$ \\
\hline \multirow{5}{*}{$\begin{array}{l}\text { Boundary } \\
\text { conditions }\end{array}$} & $\begin{array}{l}\text { Exterior } \\
\text { (variant 1) }\end{array}$ & $\begin{array}{l}\text { Mass Flow-Rate } \\
\text { Turbulent intensity } \\
\text { Hydraulic Diameter } \\
\text { Temperature } \\
\text { Internal Emissivity } \\
\text { Spec. Mass Fractions } \\
\left(\mathrm{H}_{2} \mathrm{O}\right)\end{array}$ & $\begin{array}{l}4,73 \mathrm{~kg} / \mathrm{s} \\
10 \% \\
0,856 \mathrm{~m} \\
-10{ }^{\circ} \mathrm{C} \\
1 \\
0,0013\end{array}$ \\
\hline & $\begin{array}{l}\text { Exterior } \\
\text { (variant 2) }\end{array}$ & $\begin{array}{l}\text { Mass Flow-Rate } \\
\text { Turbulent intensity } \\
\text { Hydraulic Diameter } \\
\text { Temperature } \\
\text { Internal Emissivity } \\
\text { Spec. Mass Fractions } \\
\left(\mathrm{H}_{2} \mathrm{O}\right)\end{array}$ & $\begin{array}{l}4,73 \mathrm{~kg} / \mathrm{s} \\
10 \% \\
0,856 \mathrm{~m} \\
-15^{\circ} \mathrm{C} \\
1 \\
0,00081\end{array}$ \\
\hline & Interior & $\begin{array}{l}\text { Mass Flow-Rate } \\
\text { Turbulent intensity } \\
\text { Hydraulic Diameter } \\
\text { Temperature } \\
\text { Internal Emissivity } \\
\text { Spec. Mass Fractions } \\
\left(\mathrm{H}_{2} \mathrm{O}\right)\end{array}$ & $\begin{array}{l}14,95 \mathrm{~kg} / \mathrm{s} \\
10 \% \\
1,162 \mathrm{~m} \\
21,5{ }^{\circ} \mathrm{C} \\
1 \\
0,008 \\
\end{array}$ \\
\hline & Mixture & Flow Rate Weighting & 0,8 \\
\hline & Exhaust & Flow Rate Weighting & 0,2 \\
\hline $\begin{array}{l}\text { Solution } \\
\text { method }\end{array}$ & $\begin{array}{l}\text { Pressure- } \\
\text { Velocity } \\
\text { Coupling }\end{array}$ & SIMPLE & \\
\hline
\end{tabular}

\subsection{Graphical output of simulations}

Substantial outputs of our simulations are surface temperatures and values of relative humidity on the chamber walls and in its vertical section and also air temperature distribution model at the outlet of the chamber. The distribution of temperatures is inhomogeneous, frequency of occurrence of temperature and humidity in plane at the outlet of mixing chamber is shown in figure 14 and 15.
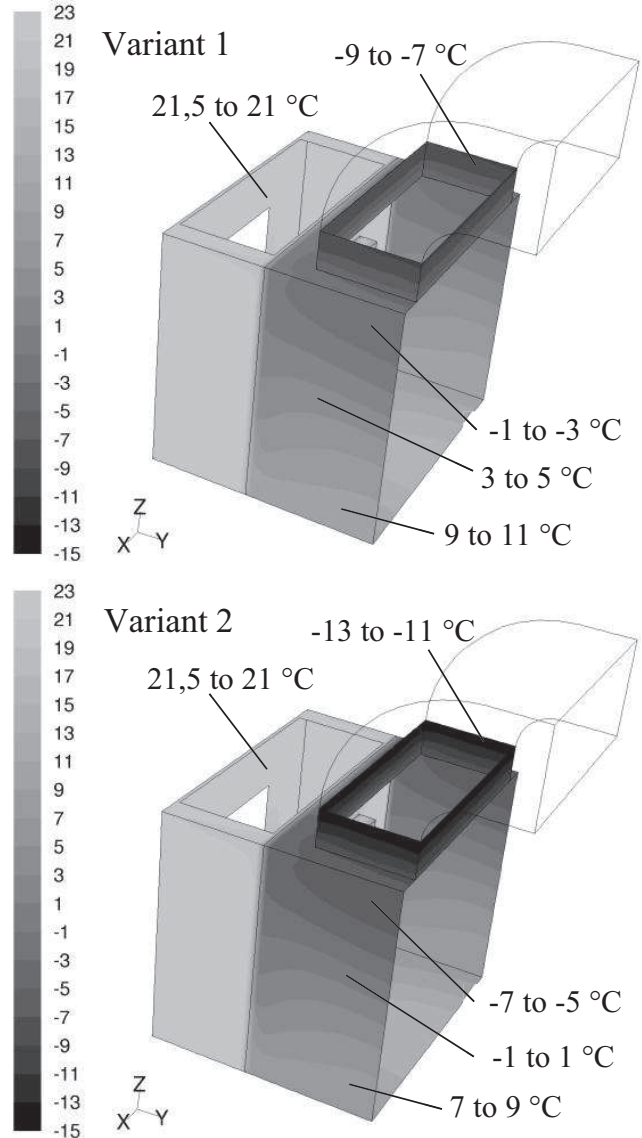

Fig. 10. Surface temperature $t_{a}\left({ }^{\circ} \mathrm{C}\right)$
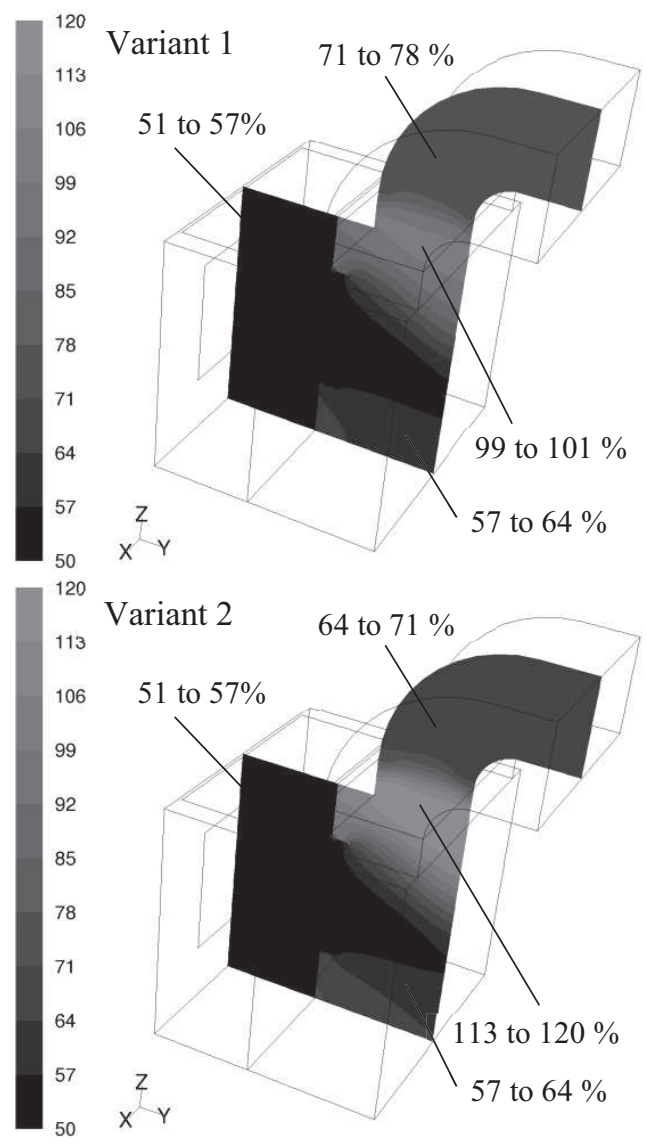

Fig. 11. Relative humidity $\varphi(\%)$ in section 

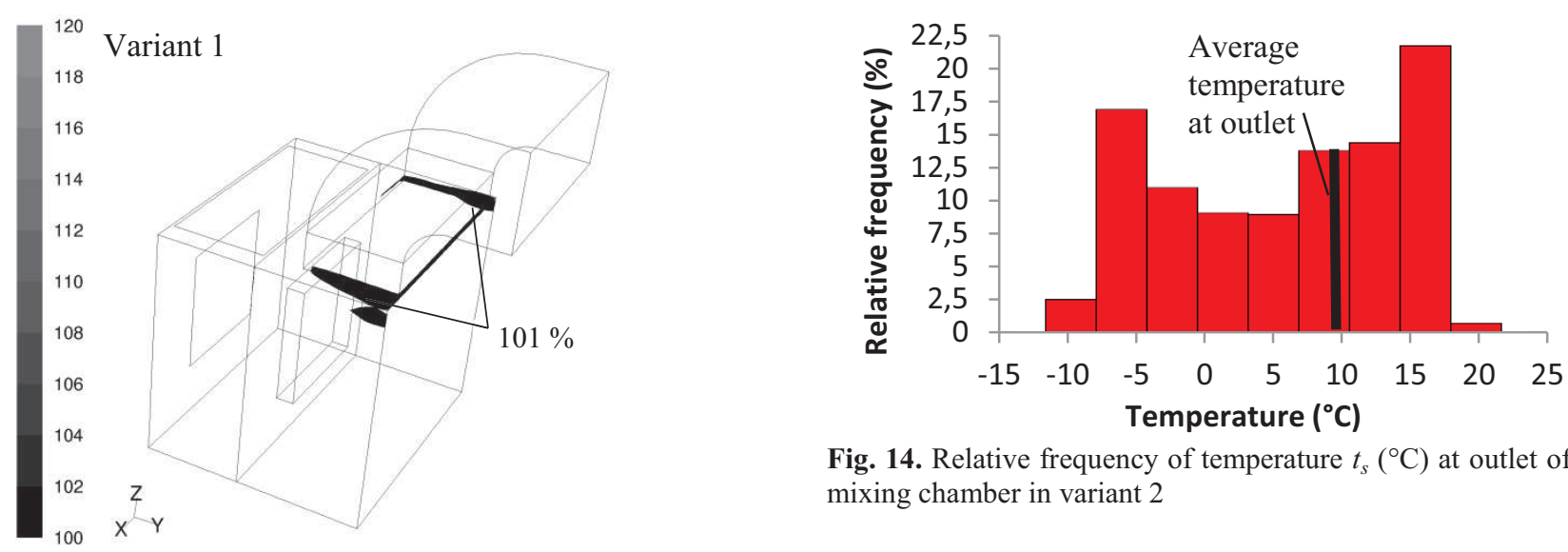

Fig. 14. Relative frequency of temperature $t_{s}\left({ }^{\circ} \mathrm{C}\right)$ at outlet of mixing chamber in variant 2
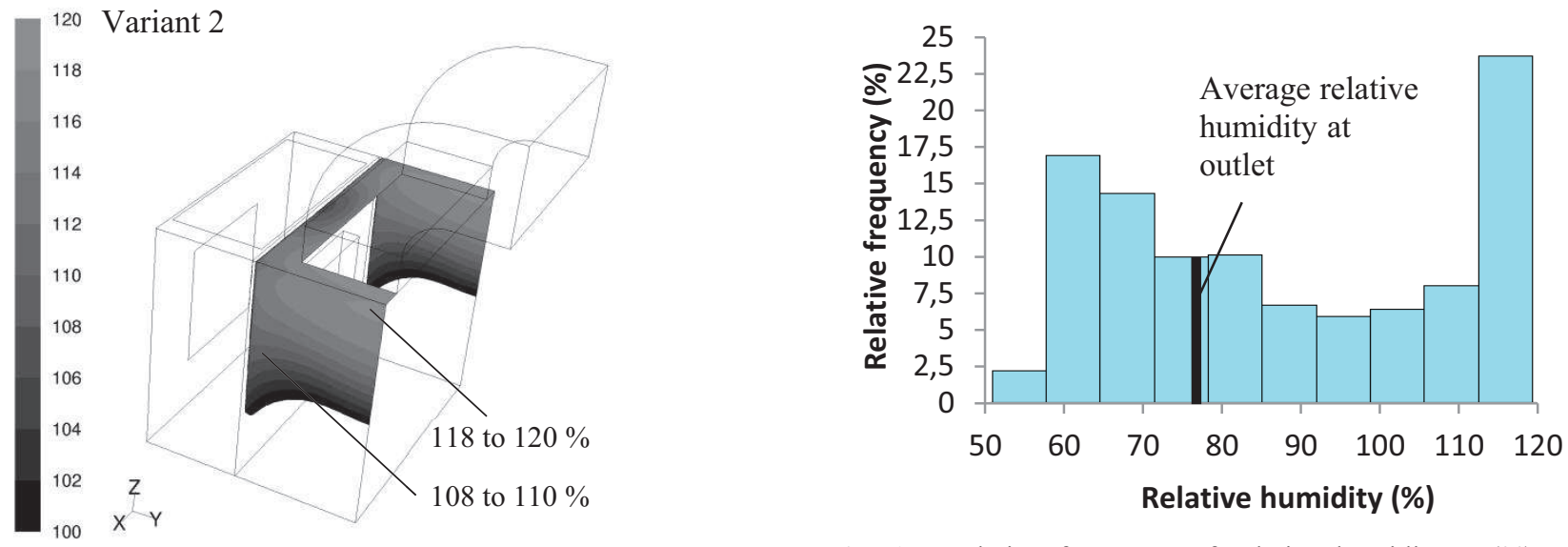

Fig. 12. Relative humidity $\varphi(\%)$ on walls of mixing chamber

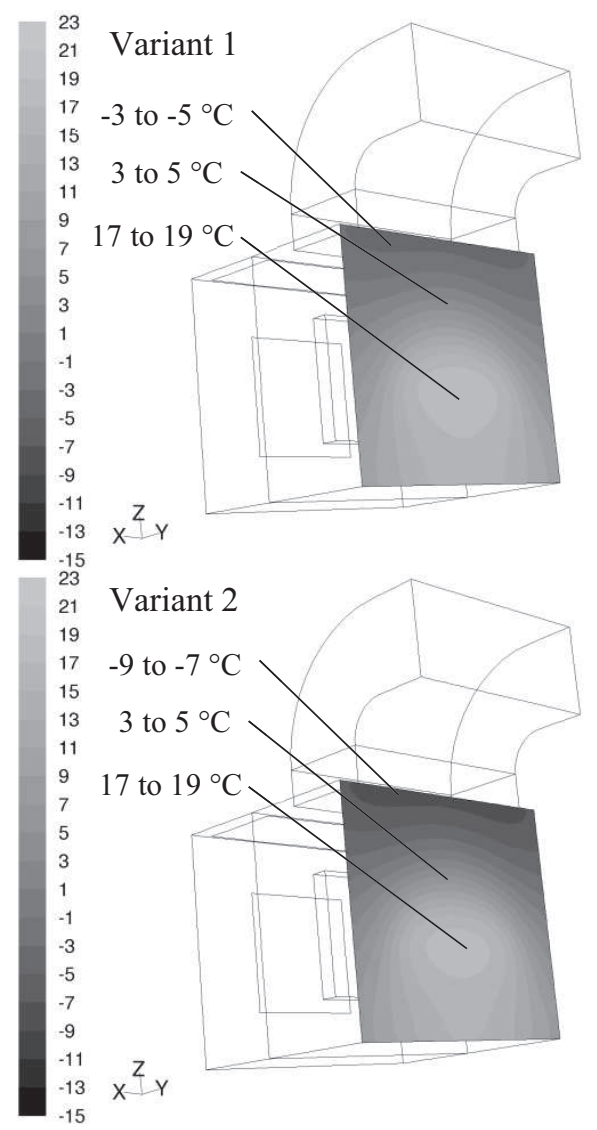

Fig. 13. Air temperature distribution $t_{s}\left({ }^{\circ} \mathrm{C}\right)$ after mixing at the mixing chamber output

Fig. 15. Relative frequency of relative humidity $\varphi(\%)$ at outlet of mixing chamber in variant 2

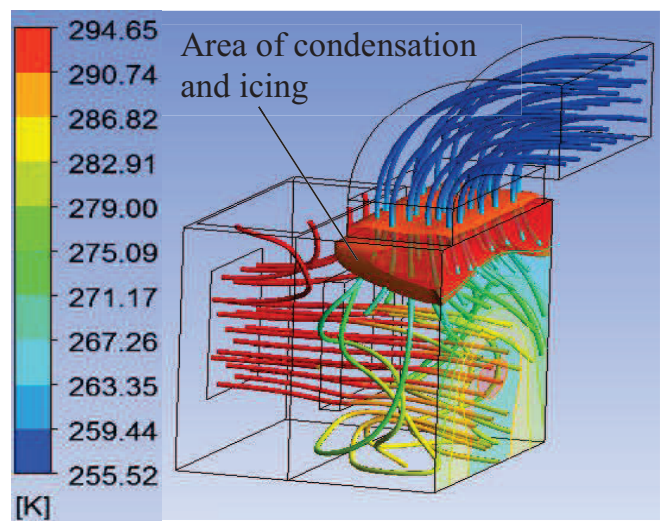

Fig. 16. Display of thermally coloured streamlines with marked areas of condensation at temperature $t_{e}=-15^{\circ} \mathrm{C}$

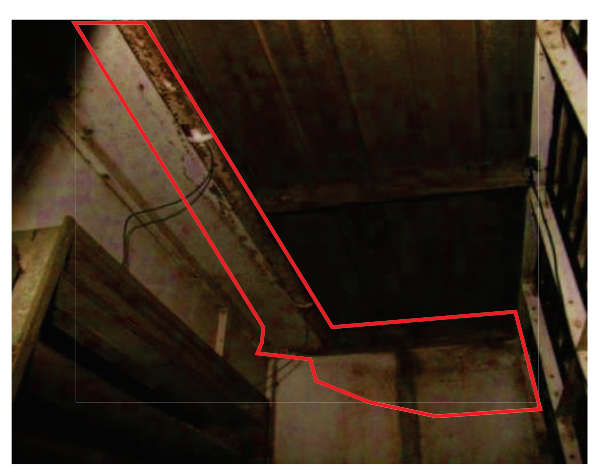

Fig. 17. Area of corrosion in mixing chamber 


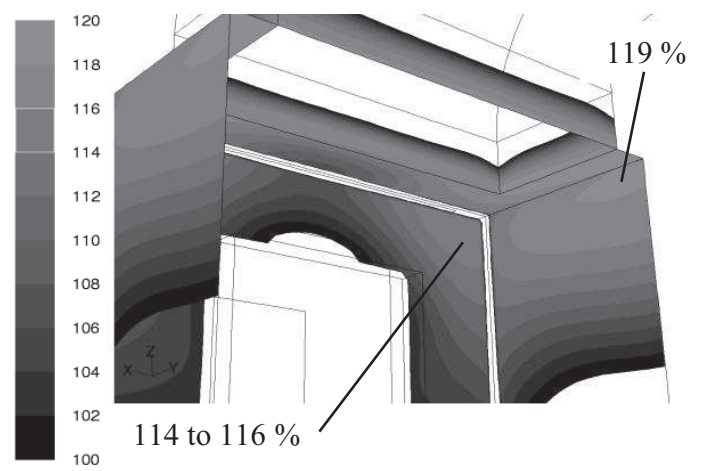

Fig. 18. Area of condensation (display of relative humidity $\varphi$ for variant 2) of mixing chamber using CFD model

\section{Discussion of results and conclusion}

The obtained simulation results imply that the highest condensation of water vapour occurs in the position of the outside flap and on upper parts of walls - closer to adjacent filters (figure 11,12,16). If we compare the real occurrence of corrosion in the mixing chamber with areas of highest relative humidity, we obtain very satisfying match (figure 17 and figure 18).

Climate data from the reference year 2012 showed that incidence of temperature below $-10{ }^{\circ} \mathrm{C}$ is 208 hours per year and 45 hours for temperature below $-15^{\circ} \mathrm{C}$, which means that there is undesirable condensation and freezing for 10 days per year.

Condensation of water vapour has a major impact on service life and hygienic safety of air handling unit. Based on the obtained results, we assume that condensation on walls of the mixing chamber occurs even if the mixing ratio line connecting mixed states of air is a secant and also about a tangent to the saturation curve, but the final position of state of air is located in the area of unsaturated water vapour. Although the experimentally obtained results are not $100 \%$ conclusive, due to absence of continuous and long-term measurements of all substantial parameters and simultaneous observation of condensation phenomena on surfaces of the AHU, we conclude that they support the validity of our initial hypothesis of condensation or freezing of water vapour during mixing even in the case when the mixing ratio line is secant or tangent to the saturation curve, but the final position of state of air is located in the area of unsaturated water vapour.

Another interesting finding is the fact (supported by simulation and also experimentally) that air flows exiting the chamber are separated having very different temperature and humidity - there is not complete unification of temperature in the whole cross-section of the given chamber - see figure 14 and 15. Even though the mean temperature and humidity of the exhaust air calculated using simulations corresponds perfectly with readings of $h-x$ diagram, physically this temperature at the outlet is not reached and shows significant deviations from the mean value. As a result of predominance of momentum forces during forced convection over buoyancy forces, the distribution of temperatures at the outlet of mixing chamber shows warmer air in the bottom part and colder in the upper part. Hence there is a probable risk of condensation and freezing on the upper part of filter, which would result in more intensive proliferation of various microorganisms. Icing of the unit has been physically confirmed. There was significant freezing of the upper water nozzles and formation of icicles at temperatures close $-15^{\circ} \mathrm{C}$. It had a negative impact on the operation of the air washer, which had to be turned off during this period, thus disturbing the internal microclimate conditions necessary for technology of production. Icing emerged also on adjacent filters having a major impact on the disruption of hygienic safety and partly on service life of some components of the air handling unit.

\section{Acknowledgements}

This work has been supported from the state budget of the Czech Republic, through the Specific research at universities of the Ministry of education youth and sports, the grant No. FAST-S-14-2372.

\section{References}

1. ČSN EN 13779 Větrání nebytových budov. Praha: Český normalizační institut, (2010). (in Czech)

2. ČSN EN 15780 Větrání budov - Vzduchovody Čistota vzduchotechnických zařízení. Praha: Český normalizační institut, 2. návrh (2012). (in Czech)

3. ČSN EN 130553+A1. Praha: Český normalizační institut, (2010). (in Czech)

4. A.R. Febbraro. Keep AHU parts clean to improve indoor air quality. AFE Facilities Engineering Journal. 34.1, 32-33. (2007)

5. Z. Lu, W.Z. Lu, J.L. Zhang, and D.X. Sun. Microorganisms and particles in AHU systems: Measurement and analysis. Building and Environment. 44 ,694-698. (2009)

6. Z. Peihong, Ventilation and humidity considerations for IEQ in shower and locker rooms. In Association E. Indoor environmental quality problems, research and solutions, 317-324. (2006)

7. G. Gong, C. Xu, J. Jiao, Y. Liu, S. Xie, Investigation of moisture condensation on papermaking plant envelopes in high humidity environment by orthogonal analysis and CFD simulation. Building and Environment. 46, 1639-1648. (2011)

8. O. Šikula, Programová řešení základních úprav vlhkého vzduchu (II). TZB- info, (2005), (in Czech)

9. O. Šikula, J. Mohleníková, J. Plášek. Thermal CFD Analysis of Tubular Light Guides. Energies. 6, 63046321. doi:10.3390/en6126304 (2013)

10. O. Šikula, K. Ponweiser, Untersuchung der Ursachen für Rauklimaprobleme in einer Schwimmbadhalle mittels CFD- Simulation. In Building Performance Simulation in a Changing Enviroment. Third German- austrian IBPSA conference, 311-315, (2010).

11. ANSYS FLUENT Theory Guide. ANSYS Help System: release 14.0 [online], no. 1. (2011) 